\title{
Trends of Sorghum Crop in Northern Telangana Zone
}

\author{
R. Srinivas* and D. Srinivasa Chary \\ Department of Statistics \& Mathematics, College of Agriculture, Professor Jayashankar \\ Telangana State Agricultural University, Rajendranagar, Hyderabad, India \\ *Corresponding author
}

\section{A B S T R A C T}

\begin{tabular}{|c|}
\hline Keywords \\
\hline $\begin{array}{l}\text { Sorghum crop, } \\
\text { Northern Telangana } \\
\text { Zone }\end{array}$ \\
\hline Article Info \\
\hline $\begin{array}{l}\text { Accepted: } \\
18 \text { November } 2020 \\
\text { Available Online: } \\
10 \text { December } 2020\end{array}$ \\
\hline
\end{tabular}

Attempts have been made to examine the trends and forecasting in area, production and productivity of Sorghum crop in Northern Telangana Zone. Linear and compound growth rates were calculated for this purpose. Ten growth models were fitted to the area, production and productivity of Sorghum crop and bestfitted model for future projection was chosen based upon least Residual Mean Square (RMS) and significant $\mathrm{Adj}^{R^{2}}$. Besides, the important assumption of randomness of residuals was tested using one sample run test. The reference period of study was from $1979-80$ to $2015-16$ and it was carried out in Northern Telangana Zone.

\section{Introduction}

Sorghum bicolour ssp. Verticilliflorum is believed to be the progenitor of cultivated sorghum (Harlan, 1972). It is cultivated in wide geographic areas in the Africa, Asia, America and the Pacific regions. It is the fifth most important cereal crop in the world, after wheat, maize, rice and barley whereas in India, sorghum is the third large cereal crop after rice and wheat. But, sorghum is second major crop in Africa after maize. It is a staple food, produced and consumed by millions of rural poor in South Asia (SA) and SubSaharan Africa (SSA).

In Northern Telangana Zone the major growing districts are Adilabad (5155 thousand ha), Nizamabad (978 thousand ha) and Kariminagar (653 thousand ha) Production are Adilabad (3406 thound tonne), Nizamabad (857 thousand tonne) and Kariminagar (426 thousand tonne). Productivity of Districts are Adilabad (660 $\mathrm{kg} / \mathrm{ha})$, Nizamabad (876 kg/ha) and Kariminagar (652 kg/ha).

During last 10 years the trends in area showing decreasing downtrend and production, productivity of sorghum in the three districts of Northern Telangana Zone have shown upward trend. The recent year's harvest price of sorghum is also increasing.

The present study is based on 36 years of data i.e., from 1979 to 2015 of Sorghum in 
Northern Telangana Zone. The linear growth rate (LGR) and compound growth rate (CGR) for the crop characteristics i.e., area, production and productivity of Sorghum crop in Northern Telangana Zone are estimated by fitting the following functions, the analysis of the data has been carried out by using data on area production and productivity obtained from web site: www.indian stat.com.

All India total sorghum production has registered a constant growth rate of $0.10 \%$ per annum during the period 1967-68 to 20102011 which can be mainly attributed to negative production of kharif sorghum rather than positive growth in rabi sorghum production. Though, kharif sorghum yield growth rates were relatively higher, it could not offset the declining growth rates in production, as the growth rates in kharif sorghum area were negative and high. Just opposite is true in case of rabi sorghum where the area decline was not sufficient to undermine the yield growth, thus resulting in positive production growth rates.

Singh and Ranjan (1998) analysed growth performance of principal food grain crops in North Bihar and India over the period from 1970-71 to 1994-95 and it was revealed that production recorded positive growth rates during post-green revolution period. There has not been a substantial increase in area under rice during the period under study. Moreover, a declining trend in rice area has been observed during early 1990s.

Chattopadhyay and Das (2000) estimated growth rates and performance of agriculture in West Bengal particularly during the left front rule in the state. After making necessary adjustments in the data they found that the rate of growth of agricultural production in West Bengal during the left front rule has been certainly higher than that during the preleft front.
Babu Reddy (2001) computed the compound growth rates for area, production and yield of Indian coffee as 2.86, 4.66 and $2.25 \%$ for the period $1950-51$ to $1999-2000$. He concluded that both expansion of area and improvement in yield have contributed to the growth in production. He also estimated growth rates for export volumes, unit value and export earnings of Indian coffee as 6.10, 8.14 and $14.74 \%$ during the period $1980-81$ to 1999 2000. Mamatha et al., (2002) made an attempt to study the trend in area, production, productivity and export of cashew in India. The authors concluded that the growth rate in area, production and productivity of cashew were positive and showed increasing trend in the states of Karnataka, Tamil Nadu, West Bengal and Andhra Pradesh, but in Goa, Kerala, Orissa, production has decreased over the years.

Sebastian et al., (2004) made an attempt to estimate the growth rates in area, production and productivity of cashew in Kerala during the period 1952-53 to 1999-2000. They divided the whole period into two sub-periods viz., period I (1952-53 to 1975-76) and Period II (1976-77 to 1999-2000). They concluded that the growth rate in area were positive for the entire period with stagnant production and declining productivity.

\section{Materials and Methods}

\section{Methodology for the estimation of growth rates}

The study was based on 36 years of data i.e., from 1979-80 to 2015-16. Keeping the objectives in view, linear growth rate (LGR) and compound growth rate (CGR) for the crop characteristics i.e., area, production and productivity of major crops in Northern Telangana Zone is estimated by fitting the following functions. 


\section{Methodology for fitting the trend equations}

The trend equations were fitted by using different growth models. Growth models are nothing but the models that describe the behaviour of a variable overtime. The growth models taken under consideration here are as follows.

\section{Linear function}

A linear model is one in which all the parameters appear linearly.

The mathematical equation is given by

$Y_{t}=a+b t$

Where

$Y_{t}$ is the dependent variable i.e., area, production and productivity

$\mathrm{t}$ is the independent variable, time in years

$\mathrm{a}$ and $\mathrm{b}$ are the constants

The constants ' $a$ ' and ' $b$ ' are estimated by applying the Ordinary Leasts Square approach.

\section{Logarithmic function}

This model shows very rapid growth, followed by slower growth

The mathematical equation is given by

$\mathrm{Y}_{\mathrm{t}}=\mathrm{a}+\mathrm{b} \ln (\mathrm{t})$

Where,

$\mathrm{Y}_{\mathrm{t}}$ is the dependent variable i.e., area, production and productivity

$t$ is the time in years, independent variable ' $a$ ' and ' $b$ ' are constants
The constants ' $a$ ' and ' $b$ ' are estimated by applying the Ordinary Least Squares approach.

\section{Inverse function}

Inverse curve shows a decreasing growth.

Inverse fit is given by the equation

$Y_{t}=a+b / t$

Where,

$Y_{t}$ is the dependent variable i.e., area, production and productivity

$\mathrm{t}$ is the independent variable, time

'a' and 'b' are parameters

The parameters can be estimated by the method of Ordinary Least Squares (OLS).

\section{Quadratic function}

This function is useful when there is a peak or a trough in the data of past periods.

Quadratic fit is given by the equation

$Y_{t}=a+b t+c t^{2}$

Where,

$\mathrm{Y}_{\mathrm{t}}$ is the dependent variable i.e., area, production and productivity

$\mathrm{t}$ is the independent variable, time in years

$\mathrm{a}, \mathrm{b}$ and $\mathrm{c}$ are constants

The constants can be calculated by applying the method of ordinary least squares approach. 


\section{Cubic function}

This function is useful when there is or has been, two peaks or two troughs in the data of past periods.

Cubic fit or third degree curve is given by the equation:

$Y_{t}=a+b t+c t^{2}+d t^{3}$

Where,

$\mathrm{Y}_{t}$ is the dependent variable i.e., area, production and productivity

$\mathrm{t}$ is the independent variable, time in years

$\mathrm{a}, \mathrm{b}, \mathrm{c}$ and $\mathrm{d}$ are parameters

The parameters are calculated by ordinary least squares technique.

\section{Compound function}

This function is useful when it is known that there is or has been, increasing growth or decline in past periods

Compound fit is given by

$\mathrm{Y}_{\mathrm{t}}=a b^{\mathrm{t}}$

Or $\ln \mathrm{Y}_{\mathrm{t}}=\ln \mathrm{a}+\mathrm{t} \ln \mathrm{b}$

Where,

$Y_{t}$ is the dependent variable, area, production and productivity

$t$ is the independent variable, time in years

$\mathrm{a}$ and $\mathrm{b}$ are parameters or constants

The constants can be obtained by using ordinary least squares technique.

\section{S-curve}

S-curve fit is given by

$\mathrm{Y}_{\mathrm{t}}=\operatorname{Exp}(\mathrm{a}+\mathrm{b} / \mathrm{t}) \quad$ or $\quad \ln \mathrm{Y}_{\mathrm{t}}=\mathrm{a}+\mathrm{b} / \mathrm{t}$

Where,

$\mathrm{Y}_{\mathrm{t}}$ is the dependent variable, area, production and productivity

$\mathrm{t}$ is the independent variable, time in years

$\mathrm{a}$ and $\mathrm{b}$ are parameters or constants

Ordinary Least Squares (OLS) method can be applied to estimate the parameters of the model.

\section{Growth function}

The fit is given by

$Y_{t}=\operatorname{Exp}(a+b t)$ or $\quad \ln Y_{t}=a+b t$

Where,

$\mathrm{Y}_{\mathrm{t}}$ is the dependent variable, area, production and productivity

$t$ is the independent variable, time in years

$\mathrm{a}$ and $\mathrm{b}$ are parameters or constants

The constants are obtained by ordinary least squares technique.

\section{Power function}

The fit is given by the equation

$\mathrm{Y}_{\mathrm{t}}=\mathrm{at}^{\mathrm{b}} \quad$ or $\quad \ln \mathrm{Y}_{\mathrm{t}}=\ln \mathrm{a}+\mathrm{b} \ln (\mathrm{t})$

Where,

$\mathrm{Y}_{\mathrm{t}}$ is the dependent variable, area, production and productivity 
$\mathrm{t}$ is the independent variable, time in years

$\mathrm{a}$ and $\mathrm{b}$ are parameters or constants

The constants are calculated by ordinary least squares technique.

The fit is similar to exponential fit, but produces a forecast curve that increases or decreases at different rate.

\section{Exponential fit}

If, when the values of $t$ are arranged in an arithmetic series, the corresponding values of $y$ form a geometric series, the relation is of the exponential type.

The function of this type can be given by

$Y_{t}=a \operatorname{Exp}(b t) \quad$ or $\quad \ln Y_{t}=\ln a+(b t)$

Where,

$\mathrm{Y}_{\mathrm{t}}$ is dependent variable i.e., area, production and productivity

$\mathrm{t}$ is independent variable, time in years

$\mathrm{a}$ and $\mathrm{b}$ are constants

The constants are calculated by ordinary least squares technique

Methodology for the estimation of future projections

The future projections of area, production and productivity of major crops in Northern Telangana Zone up to 2020 AD were estimated upon the best fitted growth model used for fitting the trend equations.

\section{Methodology for the best fitted model}

The choice of the trend equation amongst the available alternatives is very crucial. Many researchers use coefficient of multiple determination, $\mathrm{R}^{2}$ or adjusted $\mathrm{R}^{2}\left(\overline{\mathrm{R}}^{2}\right)$ as the criterion of model selection.

$$
\begin{aligned}
& R^{2}=\frac{\text { EXPLAINEDVARIATION }}{\text { TOTALVARIATION }}=\frac{\sum_{i=1}^{n}\left(\widetilde{Y}_{\bar{i}}-Y\right)^{2}}{\sum_{i=1}^{n}\left(\bar{Y}_{\overline{\bar{r}}}-\bar{Y}\right)^{2}} \\
& \operatorname{Adj}^{2}=\left(\boldsymbol{R}^{2}\right)=R^{2}-\left[\frac{K-1}{N-K}\right]\left(1-R^{2}\right)
\end{aligned}
$$

Where,

$\mathrm{K}$ is the number of constants in the equation

$\mathrm{N}$ is the total number of observations

It was observed that $\mathrm{R}^{2}$ is not enough to examine goodness of fit of a model (Reddy, 1978). So in addition to adj $R^{2}$, the residual mean square (RMS) which will also measure the accuracy in forecasting is the best criterion to choose a model from among the alternatives.

Residual mean square $=\frac{\sum\left(y_{i}-\hat{y}_{i}\right)^{2}}{\text { Residual deg rees of freedom }}$

In the present study, the model with least residual mean square (RMS) and significant adj $\mathrm{R}^{2}$ was considered to be the best fitted model.

Before choosing a model, one should be certain that the disturbance term satisfies all the conditions of randomness, nonautocorrelation, homoscedasticity and normality. In the present study, an attempt has been made to verify the most important assumption of randomness of residuals.

\section{Test for randomness of residuals}

Non-parametric one sample run test can be used to test the randomness of residuals. A run is defined as a succession of identical 
symbols in which the individual scores or observations originally were obtained. For example, suppose a series of binary events occurred in this order:

$++++--+--++-+-$

This sample of scores begins with a run of four pluses. A run of two minuses follows, then comes another run of one plus and then a run of three minuses and so on. The total runs in the above example are 8 .

If very few runs occur, a time trend or some bunching owing to lack of independence is suggested and if many runs occur, systematic short period cyclical fluctuations seem to be influencing the scores.

Let ' $n_{1}$ ', be the number of elements of one kind and ' $\mathrm{n}_{2}$ ' be the number of elements of the other kind in a sequence of $\mathrm{N}=\mathrm{n}_{1}+\mathrm{n}_{2}$ binary events. For small samples i.e., both $n_{1}$ and $n_{2}$ are equal to or less than 20 if the number of runs $r$ fall between the critical values, we accept the $\mathrm{H}_{0}$ (null hypothesis) that the sequence of binary events is random otherwise, we reject the $\mathrm{H}_{0}$.

For large samples i.e., if either $\mathrm{n}_{1}$ or $\mathrm{n}_{2}$ is larger than 20, a good approximation to the sampling distribution of $r$ (runs) is the normal distribution, with

Mean $=\mu_{r}=\frac{2 n_{1} n_{2}}{N}+1$

Standard deviation $=\sigma_{\mathrm{r}}=\sqrt{\frac{2 \mathrm{n}_{1} \mathrm{n}_{2}\left(2 \mathrm{n}_{1} \mathrm{n}_{2}-\mathrm{n}_{1}-\mathrm{n}_{2}\right)}{\left(\mathrm{n}_{1}+\mathrm{n}_{2}\right)^{2}\left(\mathrm{n}_{1}+\mathrm{n}_{2}-1\right)}}$

Then, $\mathrm{H}_{0}$ may be tested by

$$
z=\frac{r-\mu_{r}}{\sigma_{r}}
$$

The significance of any observed value of $\mathrm{Z}$ computed from the above formula may be determined by reference to the Standard Normal Distribution table.

\section{Results and Discussion}

In Northern Telangana Zone the area under Sorghum in 1979-80 was 382.00 thousand hectares area under this crop was drastically fall down and it was recorded and in 2015-16 was 24.14 thousand hectares and the average area during the study period (1979-80 to 2015-16) was 183.45 thousand hectares. The coefficient of variation recorded for the study period was 60.32 per cent. The linear and compound growth rates recorded during the study period were -5.52 and -7.00 per cent per annum respectively.

The area of Sorghum in Northern Telangana Zone exhibited a negative trend and has been decreasing significantly during the study period and this decrease was significant at $1 \%$ level of significance.

The production of Sorghum in Northern Telangana Zone in 1979-80 was 258 thousand tonnes and the average production during the study period (1979-80 to 2015-16) was 126.76 thousand tones with a coefficient of variation of 47.52 per cent. The linear growth rate and compound growth rate recorded for the study period were -3.55 and -4.4 per cent per annum respectively.

The production of Sorghum in Northern Telangana Zone exhibited a negative trend and has been decreasing significantly during the study period and the decrease was significant at $1 \%$ level of significance.

Regarding the productivity in Northern Telangana Zone it was $675.39 \mathrm{~kg} / \mathrm{ha}$ in 197980 and $969.94 \mathrm{~kg} / \mathrm{ha}$ in $2015-16$ and the average yield during the study period (197980 to $2015-16$ ) was $824.17 \mathrm{~kg} / \mathrm{ha}$, with the coefficient of variation of 35.86 per cent. The linear and compound growth rates during the study period were 2.56 and 2.70 per cent respectively (Fig. 1-4 and Table 1-5). 
The productivity of Sorghum had not followed a particular trend during the study period in Northern Telangana Zone and was significant at $1 \%$ level of significance.

Growth rates of area, production and productivity of the Sorghum crop for the study period (1979-80 to 2015-16) in Northern Telangana Zone were shown in the Table 1.

As a whole, the growth rates of productivity were higher than growth rates of area and production. All the three zones of Telangana State growth rates of area, production were showing negative trend. The growth rate of Productivity showing positive trend in three zones of Telangana State.

The average area and production is high in STZ and average productivity is high in NTZ.

\section{Fitting of different growth models}

Area of Sorghum in Northern Telangana Zone showed a decreasing growth pattern during the study period of $1979-80$ to $2015-16$. The results obtained by fitting all the ten growth models were presented in Table 4 . The Adj $\mathrm{R}^{2}$ values for all the models were ranging from 0.216 in case of s-curve and 0.988 in case of cubic function, respectively. For almost all the models, Adj $\mathrm{R}^{2}$ values were significant at $1 \%$ level of significance. The linear, quadratic and cubic models satisfied the assumption of randomness of residuals.

Cubic function was found to be the best trend equation for the purpose of future projection of area as it has exhibited the least RMS significant Adj $R^{2}$ and also satisfied the assumption of randomness of residuals.

Table.1 Growth rates of area, production, productivity of Sorghum in Northern Telangana Zone

\begin{tabular}{|c|c|c|c|}
\hline & Area & Production & Productivity \\
\hline Linear & $-5.52 * *$ & $-3.55^{* *}$ & $2.56^{* *}$ \\
\hline Compound & $-7 * *$ & $-4.4 * *$ & $2.7 * *$ \\
\hline C.V $(\%)$ & 60.32 & 47.52 & 35.86 \\
\hline$* *$ Significance at $1 \%$ level & $*$ Significance at 5\% level & \\
\hline
\end{tabular}

Table.2 Average area, production and productivity of sorghum in Northern Telangana Zone

\begin{tabular}{|l|c|}
\hline Items & Telangana State \\
\hline Area('000ha) & 183.45 \\
\hline Production('000 tonnes) & 126.76 \\
\hline Productivity(kg/ha) & 824.16 \\
\hline
\end{tabular}

Table.3 Linear and compound growth rates of area, production and productivity of sorghum in NTZ

\begin{tabular}{|l|c|c|c|}
\hline NTZ & Area & Production & Productivity \\
\hline Linear growth rate & $-5.52^{* *}$ & $-3.55^{* *}$ & $2.56^{* *}$ \\
\hline Compound growth rate & $-7.0^{* *}$ & $-4.4^{* *}$ & $2.7^{* *}$ \\
\hline
\end{tabular}

** Significant at $1 \%$ level NTZ-Northern Telangana Zone 
Table.4 Growth models for the area, production and productivity of sorghum in Northern Telangana Zone

\begin{tabular}{|c|c|c|c|c|c|c|c|c|c|c|}
\hline \multicolumn{11}{|c|}{ Area } \\
\hline Model & Linear & Logarithmic & Inverse & Quadratic & Cubic & Compound & Power & $\begin{array}{c}\text { S- } \\
\text { Curve }\end{array}$ & Growth & Exponential \\
\hline Adj R2 & $0.984 * *$ & $0.866 * *$ & $0.405 * *$ & $0.988 * *$ & $0.988 * *$ & $0.912 * *$ & $0.629 * *$ & $0.216 * *$ & $0.912 * *$ & $0.912 * *$ \\
\hline RMS & 191.46 & 1642.03 & 7291.2 & 142.67 & 141.7 & 2104.74 & 20960 & 2092 & 18841 & 2088.64 \\
\hline Runs & 17 & 5 & 3 & 12 & 10 & 9 & 3 & 5 & 3 & 9 \\
\hline \multicolumn{11}{|c|}{ Production } \\
\hline Adj R2 & $0.647 * *$ & $0.538 * *$ & $0.304 * *$ & $0.66^{* *}$ & $0.692 * *$ & $0.638 * *$ & $0.425 * *$ & $0.169 * *$ & $0.638 * *$ & $0.638 * *$ \\
\hline RMS & 1281.5 & 1674.9 & 2527.31 & 1196.87 & 1083 & 1704.13 & 3551.8 & 1701.98 & 2713.7 & 1704.22 \\
\hline Runs & 15 & 13 & 11 & 15 & 16 & 10 & 10 & 10 & 15 & 10 \\
\hline \multicolumn{11}{|c|}{ Productivity } \\
\hline Adj R2 & $0.588 * *$ & $0.421 * *$ & $0.106^{*}$ & $0.576 * *$ & $0.646 * *$ & $0.569 * *$ & $0.407 * *$ & $0.093^{*}$ & $0.569 * *$ & $0.569 * *$ \\
\hline RMS & 36010 & 50626.03 & 78098 & 36008.49 & 29225 & 37921.06 & 78476 & 37684.5 & 46517 & 37691.16 \\
\hline Runs & 16 & 14 & 6 & 16 & 19 & 14 & 9 & 14 & 19 & 14 \\
\hline
\end{tabular}

Table.5 Projections of area, production and productivity sorghum in Northern Telangana Zone

\begin{tabular}{|l|c|c|c|}
\hline Year & $\begin{array}{c}\text { Area } \\
\text { ('000 ha) }\end{array}$ & $\begin{array}{c}\text { Production } \\
\text { (' } \mathbf{0 0 0} \text { tonnes) }\end{array}$ & $\begin{array}{c}\text { Productivity } \\
\text { (kg/ha) }\end{array}$ \\
\hline $\mathbf{2 0 1 6 - 2 0 1 7}$ & 9 & 41.07 & 1209.82 \\
\hline $\mathbf{2 0 1 7 - 2 0 1 8}$ & 7 & 46.51 & 1240.92 \\
\hline $\mathbf{2 0 1 8 - 2 0 1 9}$ & 6 & 42.64 & 1270.44 \\
\hline $\mathbf{2 0 1 9 - 2 0 2 0}$ & 4 & 38.53 & 1298.38 \\
\hline $\mathbf{2 0 2 0 - 2 0 2 1}$ & 1 & 34.20 & 1324.79 \\
\hline
\end{tabular}


Fig.1 Average area, production and productivity of sorghum in three zones of Telangana State

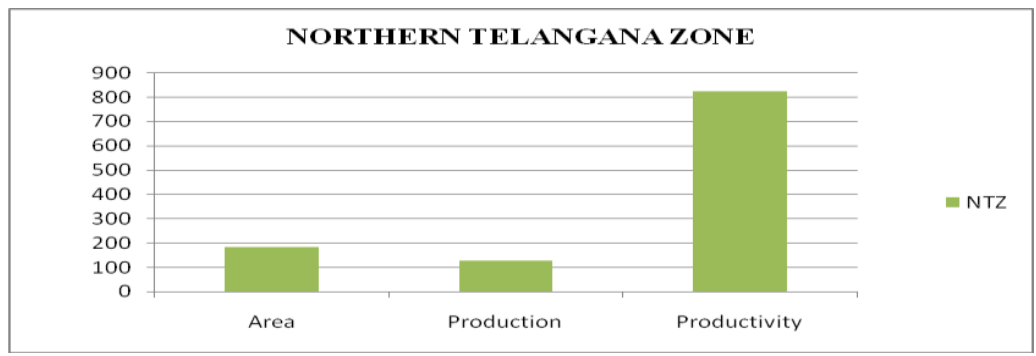

Fig.2 Trend of sorghum area in Northern Telangana Zone of Telangana State

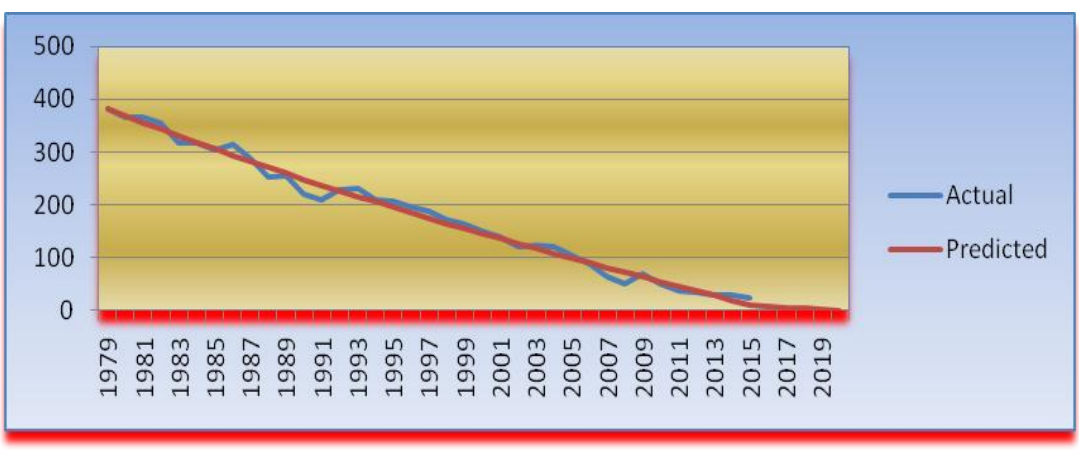

Fig.3 Trend of sorghum production in Northern Telangana Zone of Telangana State

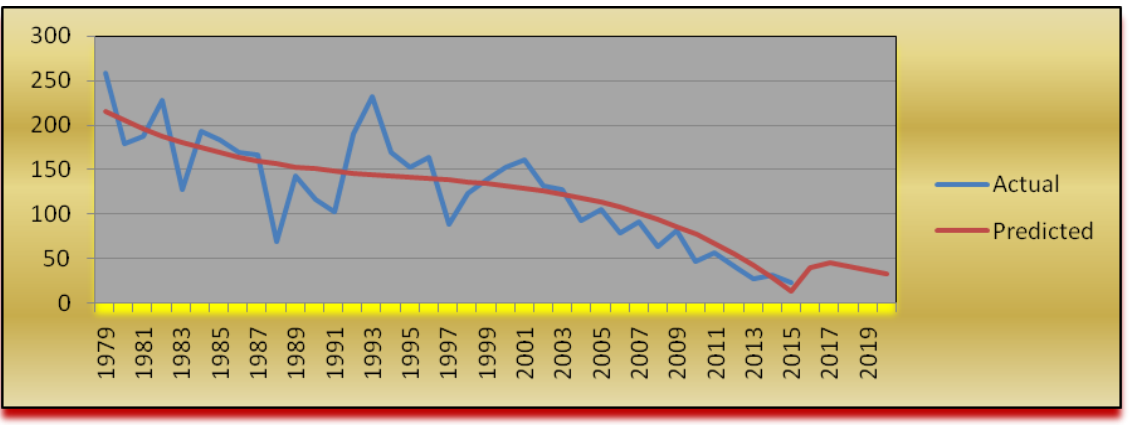

Fig.4 Trend of sorghum productivity in Northern Telangana Zone of Telangana State

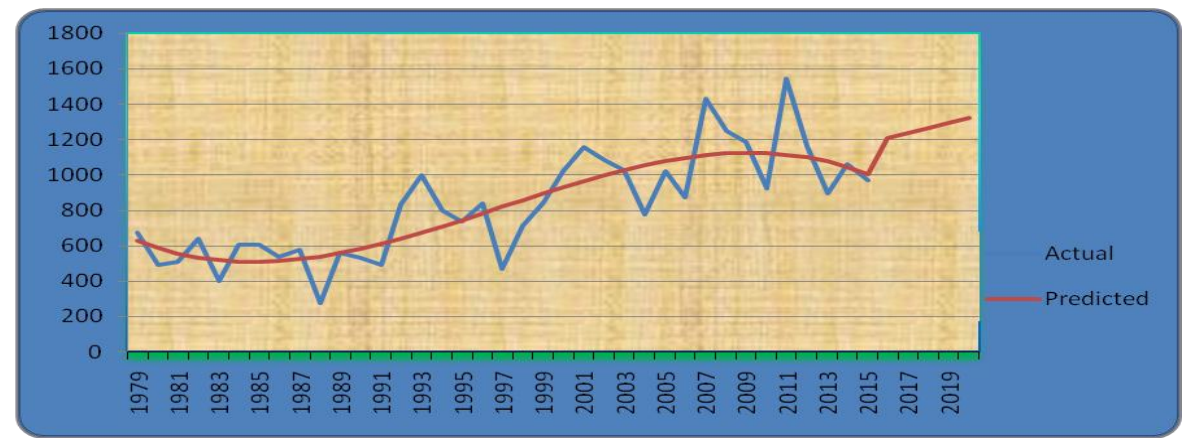


The Production of Sorghum in Northern Telangana Zone not follows the particular growth pattern during the study period. The results obtained by fitting all the ten growth models were presented in Table 4 . The Adj $\mathrm{R}^{2}$ values for all the models were ranging between 0.169 in case of s-curve and 0.692 in case of cubic function. For almost all the models Adj $\mathrm{R}^{2}$ values were significant at $1 \%$ level of significance. The linear, logarithmic, inverse, cubic and growth functions satisfied the assumption of randomness of residuals.

Cubic function was found to be the best trend equation for the purpose future projection of production as it has exhibited the least RMS and significant Adj $R^{2}$ and also satisfied the assumption of randomness of residuals. The Productivity of Sorghum in Northern Telangana Zone not showed particular trend but increased productivity during the study period. The results obtained by fitting all the ten growth models were presented in Table 4 . The Adj $\mathrm{R}^{2}$ values for all the models were ranging between 0.093 in case of s-curve and 0.646 in case of cubic function respectively. For almost all the models, Adj $\mathrm{R}^{2}$ values were significant at $1 \%$ level of significance but the inverse and s-curve value were significant at $5 \%$ level of significance. Except inverse and power model remaining all the models satisfied the test of randomness of residuals.

Cubic function was found to be the best trend equation for the purpose of future projection of productivity as it has exhibited the least RMS and significant Adj $\mathrm{R}^{2}$ and also satisfied the assumption of randomness of residuals.

\section{Future Projections of Area, Production and Productivity up to $2020 \mathrm{AD}$}

The future projections of area, production and productivity of Sorghum in Northern Telangana Zone by 2020 AD were calculated and the results were presented in the Table 5 .
Area under Sorghum in Northern Telangana Zone was projected by using cubic function which was found to be best for this purpose as it had least RMS and significant Adj $\mathrm{R}^{2}$ and also fulfilled the assumption of randomness of residuals. The area under Sorghum projected by cubic function by $2020 \mathrm{AD}$ would be 1 thousand hectares which as in decreasing trend.

Regarding the production of Sorghum, cubic function was found to be the best model for future projections by $2020 \mathrm{AD}$ as it has least RMS the significant Adj $R^{2}$ and also satisfied the assumption of randomness of residuals. The projected production would be increasing at 34.20 thousand tonnes by $2020 \mathrm{AD}$.

Productivity of Sorghum was projected by using cubic function which has less RMS, significant Adj $R^{2}$ and also has showed significant runs. The future projection for productivity of Sorghum also is in increasing trend and it would be $1324.79 \mathrm{~kg} / \mathrm{ha}$ by 2020.AD.

\section{References}

Chattopadhyay, A.K and Das, P.S. 2000. Estimation of growth rate: A critical analysis with reference to West Bengal Agriculture. Indian Journal of Agricultural Economics. 55(2): 116135.

Babu Reddy, D.R. 2001. Trends in Indian coffee industry - prospects and challenges. Journal of Plantation Crops. 29(3): 22-26.

Mamatha, T.G., Gummagolamath, K.C and Shripad, P.V. 2002. Trend analysis in production and export of cashew in India. Cashew. 16(1): 13-17.

Singh, Rai, I.J., Karwasra, K.N and J.C. 1997. Regional variations in agricultural performance in India. Indian Journal of Agricultural Economics. 52(3): 374- 
386.

productivity of cashew in Kerala - A

Sebastian, S., Thomas, K.J and Thomas, E.K.

Trend Analysis. Cashew 18(3): 22-26. 2004. Area, production and

\section{How to cite this article:}

Srinivas, R. and Srinivasa Chary, D. 2020. Trends of Sorghum Crop in Northern Telangana Zone. Int.J.Curr.Microbiol.App.Sci. 9(12): 2862-2872.

doi: https://doi.org/10.20546/ijcmas.2020.912.341 